\title{
A proposal for water oxidation in photosystem II
}

\author{
Vincent L. Pecoraro, Michael J. Baldwin, M. Tyler Caudle, Wen-Yuan Hsieh and \\ Neil A. Law \\ Department of Chemistry, University of Michigan, Ann Arbor, MI 48109-1055
}

\begin{abstract}
There has been much speculation concerning the mechanism for water oxidation by Photosystem II. Based on recent work on the biophysics of Photosystem II and our own work on the reactivity of synthetic manganese complexes, we propose a chemically reasonable mechanistic model for the water oxidation function of this enzyme. An essential feature of the model is the nucleophilic attack by calcium-ligated hydroxide on an electrophilic oxo group ligated to high-valent manganese to achieve the critical O-O bond formation step. We also present a model for S-state advancement as a series of proton-coupled electron transfer steps, which has been proposed previously [Hoganson et. al., Photosynth. Res. 46, 177 (1995); Gilchrist et. al. Proc. Nat. Acad. Sci, USA. 92, 9545 (1995)], but for which we have developed model systems that allow us to probe the thermodynamics in some detail.
\end{abstract}

One of the great unsolved mysteries in bioinorganic chemistry is the mechanism of water oxidation by the oxygen evolving complex (OEC) of Photosystem II (PS II). This reaction is responsible for nearly all of the dioxygen on our planet and conceptually is the reverse reaction of respiration where dioxygen is converted back to water. Plants use an expansive artay of photopigments in Photosystem II, four manganese ions, calcium and chloride to carry out these reactions. While intensively studied for many years, only now is a picture emerging as to how this fascinating and essential chemistry may result. The scope of this article is far too limited to allow for a detailed summary of previous studies in the field; therefore, interested reader's are directed to recent reviews of this topic(ref. 1,2).

In this contribution, we will present studies that are aimed at evaluating the chemical mechanism for water oxidation that is proposed in Fig. 1. This model is in many ways similar to that proposed by G.T. Babcock(ref. 3, 4) but has significant chemical differences in the high and low $S$ states. Important features of our proposal include: 1) oxidation of the catalytic center through a coupled proton/electron transfer from the manganese cluster to a redox active tyrosyl radical, 2) the generation in the $S_{4}$ state of a strongly electophilic manganyl oxo $[\mathrm{Mn}(\mathrm{V})=\mathrm{O}]$ that can couple to a strongly nucleophilic hydroxyl group making a peroxide intermediate and 3) oxidation of the transiently formed peroxide by a second oxo bridged dimer. Additionally, we consider the thermodynamics of the system in order to evaluate implications for the energetics of water oxidation on cluster structure and reactivity.

Both G.T. Babcock(ref. 3, 4) and R.D. Britt(ref. 5) have proposed that the $S$ state transitions require proton coupled electron transfer

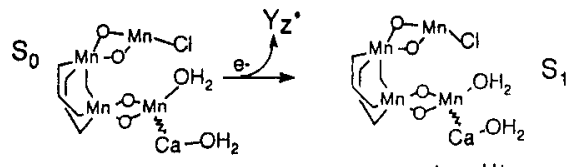<smiles></smiles><smiles>[Y17][C+]1CC1</smiles>

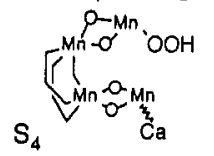

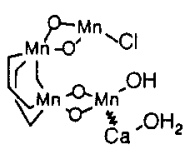

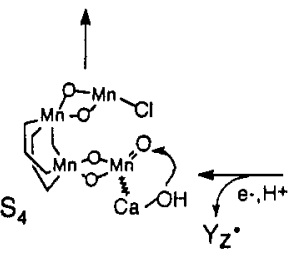

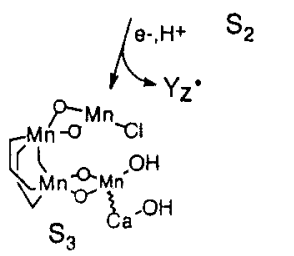

Figure 1 from the manganese cluster to a redox active tyrosine that is in close proximity to the metal center. Functionally, this process is a hydrogen atom abstraction from a manganese bound water (hydroxide) ligand to a neutral tyrosyl radical. It is estimated that the homolytic bond dissociation energy (HBDE) for a tyrosine radical is $86.5 \mathrm{kcal} / \mathrm{mol}(\mathrm{ref} .6,7)$. Thus, for $\mathrm{H}$ atom abstraction to be thermodynamically viable in this system, water/hydroxide ligation to manganese must lower the $\mathrm{HBDE}$ by over $30 \mathrm{kcal} / \mathrm{mol}$ as compared to bulk water (HBDE $=119 \mathrm{kcal} / \mathrm{mol}(\mathrm{ref} .8)$ ). 
We have prepared model compounds to evaluate whether neutral phenolic radicals are thermodynamically capable of $\mathrm{H}$ atom abstraction of protonated oxygens bound to high valent manganese. The two series of compounds we have used for these studies are shown in Fig. 2. The protonated forms of $\left[\mathrm{Mn}^{\mathrm{IN}}(\mathrm{salXn})\left(\mu_{2}-\mathrm{O}\right)\right]_{2}$ (where $\mathrm{H}_{2}$ salpn $=\mathrm{N}, \mathrm{N}^{\prime}$-disalicylidene-1,3-diaminopropane and $\mathrm{H}_{2}$ salen $=\quad \mathrm{N}, \mathrm{N}$-disalicylidene-1,2diaminoethane allow us to determine the HBDE for $\mu_{2}-\mathrm{OH}^{-}$bridges between $\mathrm{Mn}(\mathrm{TV})$ ions(ref. 9). The HBDE for terminally coordinated water has been evaluated using the dimeric $\{[\mathrm{Mn}(2-$ OHsalpn) $\left.]_{2}\left(\mathrm{OH}_{2}\right)\right\}$ complexes (where $\mathrm{H}_{3}(2$ -
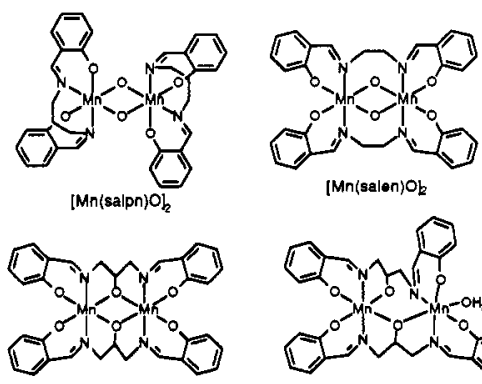

[Mn(2-OHsalpn) $]_{2}$

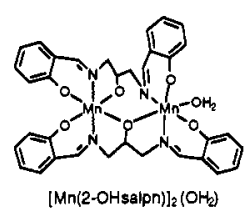

Figure 2 $\mathrm{OHsalpn})=\mathrm{N}, \mathrm{N}^{\prime}$-disalicylidene-2-hydroxy-1,3-diaminopropane) that can be prepared as $\mathrm{Mn}^{\mathrm{II}}{ }^{\text {, }}$ $\mathrm{Mn}^{\mathrm{IIN} N}$ and $\mathrm{Mn}^{\mathrm{N}}{ }_{2}$ forms (ref. 10). We have calculated the HBDE for these complexes using the generalized thermodynamic cycle described by Mayer (ref. 11) with experimental modifications necessary for evaluating these numbers in acetonitrile (ref. 9, 10). The calculated HBDE are shown in Table 1. Regardless of structure type, the HBDE for the removal of an $\mathrm{H}$ atom from $\left\{\left[\mathrm{Mn}^{\mathrm{II} / \mathrm{N}}(\mathrm{salXn})\right]_{2}\left(\mu_{2}-\mathrm{O}, \mathrm{OH}\right)\right\}$ is below $80 \mathrm{kcal} / \mathrm{mol}$. This HBDE may actually be too low for allowing water oxidation since nearly $7-10 \mathrm{kcal} / \mathrm{mol}$ of energy from $P_{680}$ would be lost on each transition. In contrast, water molecules bound terminally to $\mathrm{Mn}^{\mathrm{m}}$ have HBDE values that are very similar to that of a tyrosyl radical suggesting that efficient energy transfer from $\mathrm{Y}_{z}^{+}$to the manganese cluster could occur in PS II.

TABLE 1: Homolytic bond dissociation data for water and hydroxide-ligated manganese complexes.

\begin{tabular}{|c|c|}
\hline Complex & HBDE(ref) \\
\hline $\mathrm{Mn}^{\mathrm{III}} \mathrm{Mn}^{\mathrm{N}}(\mathrm{salpn})_{2}(\mu-\mathrm{O}, \mu-\mathrm{OH})$ & 76 (ref. 9$)$ \\
\hline $\mathrm{Mn}^{\mathrm{II}} \mathrm{Mn}^{\mathrm{N}}((3,5-\mathrm{Cl}-\mathrm{sal}) \mathrm{pn})_{2}(\mu-\mathrm{O}, \mu-\mathrm{OH})$ & 77(ref. 9) \\
\hline $\mathrm{Mn}^{\mathrm{II}} \mathrm{Mn}^{\mathrm{N}}\left(\left(3,5-\mathrm{NO}_{2}-\mathrm{sal}\right) \mathrm{pn}\right)_{2}(\mu-\mathrm{O}, \mu-\mathrm{OH})$ & 79(ref. 9) \\
\hline$\left[\mathrm{Mn}^{\mathrm{III}}(\mathrm{bpy})_{2}\right]_{2}(\mu-\mathrm{O}, \mu-\mathrm{OH})^{3+}$ & 84 (ref. 12,13 ) \\
\hline $\mathrm{Mn}_{2}(2-\mathrm{OH}(3,5-\mathrm{Cl}-\mathrm{sal}) \mathrm{pn}) \mathrm{OH}_{2}$ & 89 (ref. 10$)$ \\
\hline $\mathrm{Mn}_{2} \mathrm{II}_{2}$-OHsalpn $) \mathrm{OH}_{2}$ & 85 (ref. 10 ) \\
\hline $\mathrm{Mn}_{2}{ }_{2}^{\mathrm{III}}(2-\mathrm{OH}(3,5-\mathrm{t}-\mathrm{Bu}-\mathrm{sal}) \mathrm{pn}) \mathrm{OH}_{2}$ & 82 (ref. 10 ) \\
\hline $\mathrm{Mn}^{\mathrm{III}} \mathrm{Mn}^{\mathrm{NV}}(2-\mathrm{OH}(3,5-\mathrm{Cl}-\mathrm{sal}) \mathrm{pn}) \mathrm{OH}_{2}{ }^{+}$ & 94 (ref. 10) \\
\hline $\mathrm{Mn}^{\mathrm{II}} \mathrm{Mn}^{\mathrm{IV}}(2-\mathrm{OHsalpn}) \mathrm{OH}_{2}^{+}$ & 89 (ref. 10) \\
\hline $\mathrm{Mn}^{\mathrm{III}} \mathrm{Mn}^{\mathrm{NV}}(2-\mathrm{OH}(3,5-\mathrm{t}-\mathrm{Bu}-\mathrm{sal}) \mathrm{pn}) \mathrm{OH}_{2}^{+}$ & $86($ ref. 10$)$ \\
\hline
\end{tabular}

Assuming that both free $\mathrm{H}_{2} \mathrm{O}$ and $\mathrm{H}_{2} \mathrm{O}-\mathrm{Mn}$ are compared under identical solvent systems in equations 1-4, it is instructive to recognize that the depression of the HBDE due to water binding to manganese is a reflection of two independent processes acting in concert. We see that the HBDE for free water, eq 1a, can be written as the sum of an acid dissociation (eq 2a) and an oxidation of hydroxide (eq 3a). Equation la can be completed by accounting for the reduction of hydrogen ion in eq $4 a$.

$$
\begin{aligned}
& \mathrm{H}_{2} \mathrm{O} \rightarrow>\mathrm{H}^{*}+\mathrm{OH}^{*} \quad \text { (1a) } \quad \text { vs. } \quad \mathrm{H}_{2} \mathrm{O}-\mathrm{M}^{\mathrm{n}}->\mathrm{H}^{*}+\mathrm{HO}-\mathrm{M}^{\mathrm{n}+1} \\
& \mathrm{H}_{2} \mathrm{O}->\mathrm{H}^{+}+\mathrm{OH}^{-} \\
& \mathrm{OH}^{-}->\mathrm{OH}^{*}+\mathrm{e}^{-} \\
& \mathrm{H}^{+}+\mathrm{e}^{-}->\mathrm{H}^{\cdot} \\
& \mathrm{H}_{2} \mathrm{O}-\mathrm{M}^{\mathrm{n}}->>\mathrm{H}^{+}+\left[\mathrm{HO}-\mathrm{M}^{\mathrm{n}}\right] \\
& \text { vs. } \\
& {\left[\mathrm{HO}-\mathrm{M}^{\mathrm{n}}\right]^{-}-->\left[\mathrm{HO}-\mathrm{M}^{\mathrm{n}+1}\right]^{\cdot}+\mathrm{e}^{-}} \\
& \text {vs. } \\
& \mathrm{H}^{+}+\mathrm{e}^{-}->\mathrm{H}^{*}
\end{aligned}
$$

It is expected that the acidity of water bound to a metal will be greater than that of bulk water. The magnitude of the $\mathrm{pK}_{\mathrm{a}}$ perturbation in eq $1 \mathrm{~b}$ for the metal complex will be dependent on the size and oxidation state of the metal (which is simply a reflection of the Lewis acidity of the metal), the overall charge of the environment, and the solvent medium. This effect will occur for water bound to any metal and corresponds to approximately $5-10 \mathrm{kcal} / \mathrm{mol}$ of the decrease in HBDE for water ligated to manganese(III). The second important factor is the oxidation potential of free hydroxide versus hydroxide bound metal center (eq $3 \mathrm{~b}$ ). This term is highly dependent on the metal and its oxidation state. For $\mathrm{Mn}$ (III) $\mathrm{OH}_{(2)}-\rightarrow \mathrm{Mn}$ (IV) $\mathrm{OH}_{(2)}$ or $\mathrm{Mn}$ (II)OH $\mathrm{OH}_{(2)}->\mathrm{Mn}$ (III)OH $\mathrm{OH}_{(2)}$ it appears that $20-30 \mathrm{kcal} / \mathrm{mol}$ stabilization can be achieved (since eq $4 \mathrm{a}$ and $4 \mathrm{~b}$ are identical for both schemes, it cancels when comparing both processes). By binding to the metal, the relevant potential is no longer that of oxidizing hydroxide, but rather that of oxidizing the metal-hydroxide complex. Thus, the critical issues are the change in acidity of water and the ability to oxidize the metal. 
By recognizing the importance of acidity and potential, we may now consider what might happen if these experiments were performed with metals other than manganese. In particular, we will consider $\mathrm{Ca}^{\mathrm{II}}$ and $\mathrm{Fe}^{\mathrm{II}}$. We consider $\mathrm{Ca}^{\mathrm{II}}$ because it is also an essential metal cofactor for water oxidation, which may be a part of or in close proximity to the manganese cluster. $\mathrm{Ca}^{\mathrm{II}}$ is a strong Lewis acid and should lead to a marked $\mathrm{pK}_{\mathrm{a}}$ perturbation in equation $2 \mathrm{a}$; however, this $\mathrm{pK}_{\mathrm{a}}$ shift should lead to a maximum $10 \mathrm{kcal} / \mathrm{mol}$ decrease in HBDE. In contrast, the oxidation potential to achieve $\mathrm{Ca}^{\mathrm{III}}$ is very high and would not be expected to alter the potential with respect to hydroxide oxidation to hydroxyl radical. Thus, we would not expect $\mathrm{H}$ atom abstraction from water coordinated to $\mathrm{Ca}^{\mathrm{I}}$ to be a viable mechanism of energy transfer. In the case of iron, it might be expected that $\mathrm{Fe}^{\mathrm{II}}$ could be generated from $\mathrm{Fe}^{\mathrm{II}}$; however, going from $\mathrm{Fe}^{\mathrm{II}}$ to $\mathrm{Fe}^{\mathrm{N}}$ is probably energetically too costly. In fact, in ribonucleotide reductase $\mathrm{Fe}^{\mathrm{IV}}$ is thought to generate a tyrosyl radical and in methane monoxygenase such a species may be the active oxidant for cleaving the methane $\mathrm{C}-\mathrm{H}$ bond. Considered in this way, we may now recognize the the long sought after answer to the question of why manganese is involved in photosynthetic water oxidation and not iron. Manganese may balance the features of redox stability and acidity in order to match the energy available from $\mathrm{Y}_{z}^{+}$which could not be captured effectively by iron.

The final step in the water oxidation scheme shown in Fig. 1 invokes a two step process for water oxidation. The first step is attack of a neuclophilic hydroxide bound to $\mathrm{Ca}^{\mathrm{I}}$ (or alternatively $\mathrm{Mn}$ ) on to an electrophilic oxo group of $\mathrm{Mn}^{\mathrm{v}}$ to give hydroperoxide. The second step is a two electron oxidation of the hydroperoxide by a $\left[\mathrm{Mn}^{\mathrm{N}}\left(\mu_{2}-\mathrm{O}\right)\right]_{2}$ core. This scheme has several virtues. First, the water oxidation process is separated into two 2-electron steps rather than needing to overcome the energetic barrier of a single 4-electron conversion. Second, both steps may now have chemical precedent. We showed several years ago that $\left[\mathrm{Mn}^{\mathrm{Nv}}\left(\mu_{2}-\mathrm{O}\right)\right]_{2}$ cores were very efficient at oxidizing peroxide to dioxygen (ref. 14). Very recently Brudvig and Crabtree reported a model compound that may generate oxygen from a high valent Mn species(ref. 15). The latter reaction would, most likely require a $\mathrm{Mn}^{\mathrm{V}} \mathrm{Mn}^{\mathrm{v}}=\mathrm{O}$ dimer, though there was no direct evidence for such a species presented. Third, this chemical mechanism would explain why two dimers might be necessary for water oxidation. One dimer would generate peroxide and the other oxidize the peroxide. A functionally asymmetric dimer of dimers would also be consistent with recent data suggesting that there is differential access of small molecules to the four manganese and that there may be two dimers with differing potentials(ref. 16). Fourth, this model provides a role for $\mathrm{Ca}^{I}$ in which this metal's role is to present a hydroxide nucleophile in close proximity to the nascent $\mathrm{Mn}^{\mathrm{v}}=\mathrm{O}$ that is formed in $\mathrm{S}_{4}$.

In order to test the viability of a $\mathrm{Mn}^{\mathrm{IV}} \mathrm{Mn}^{\mathrm{v}}=\mathrm{O}$ dimer and to evaluate the physical properties of such a compound, we have examined the sequential oxidation of $\left\{[\mathrm{Mn}(2-\mathrm{OHsalpn})]_{2} \mathrm{OH}_{2}\right\}$ as shown in Fig. 3. This series has been generated in one electron steps using bulk electrolysis or chemical oxidants/reductants. In the absence of a coordinated solvent we have characterized $\mathrm{Mn}_{2}^{\mathrm{I}}$, $\mathrm{Mn}^{\mathrm{I}} \mathrm{Mn}^{\mathrm{II}}, \mathrm{Mn}^{\mathrm{II}}{ }_{2}$, and $\mathrm{Mn}^{\mathrm{II}} \mathrm{Mn}^{\mathrm{IV}}$ complexes. We have been able to generate compounds with coordinated water or hydroxide in the $\mathrm{Mn}^{\mathrm{III}}{ }_{2}, \mathrm{Mn}^{\mathrm{II}} \mathrm{Mn}^{\mathrm{IV}}$, and $\mathrm{Mn}^{\mathrm{NV}}{ }_{2}$ oxidation levels and we are now investigating the reactivity of a material that may be a $\mathrm{Mn}^{\mathrm{N}} \mathrm{Mn}^{\mathrm{v}}=0$ species. This highly desired species appears to be generated transiently by hypochlorite oxidation of $\left[\mathrm{Mn}^{\mathrm{II}} \mathrm{Mn}^{\mathrm{IV}}(2-\mathrm{OHsalpn})_{2}\right]^{+}$ according to equation 5 .

$$
\mathrm{Mn}^{\mathrm{III}} \mathrm{Mn}^{\mathrm{IV}}(2-\mathrm{OHsalpn})^{+}+\mathrm{OCl}^{-} \quad \mathrm{Mn}^{\mathrm{IV}} \mathrm{Mn}^{\mathrm{v}}(\mathrm{O})(2-\mathrm{OHsalpn})+\mathrm{Cl}^{-}
$$

This reaction is directly analogous to the preparation of mononuclear, chiral (salen) $\mathrm{Mn}^{\mathrm{V}}=\mathrm{O}$, which is used for stereoselective olefin epoxidation (ref. 17, 18). Confirmation of the production of a higher valent manganese complex comes from the observation of exclusive epoxidation of cyclohexene to form cyclohexene oxide with complete recovery of the starting $\left[\mathrm{Mn}^{\mathrm{II}} \mathrm{Mn}^{\mathrm{N}}(2\right.$ OHsalpn $\left.)_{2}\right]^{+}$. The product cyclohexene oxide is diagnostic of oxo group transfer from $\mathrm{Mn}^{\mathrm{v}}=0$ rather than allylic oxidation associated with non-specific radical oxidants. Needless to say, the possible production of such a desirable molecule is fueling intense efforts to isolate and characterize this material.

We will next address the energetics of the cycle in Fig. 1. The oxidation of water to dioxygen occurs on the lumenal side of the thylakoid membrane in a weakly acidic environment (ref. 19). Under these conditions, it is estimated that $0.89 \mathrm{~V}$ per electron are required to generate dioxygen which corresponds to the accumulation of approximately $3.6 \mathrm{~V}$ for the total conversion. The reaction center chlorophyll $\mathrm{P}_{680}$ is capable of generating $1.8 \mathrm{~V}$ of oxidizing power on each photochemical step. However, $0.6 \mathrm{~V}$ is lost to the reducing side of PS II leaving $1.2 \mathrm{~V}$ of oxidation power to drive water splitting(ref. 19). The oxidation of the redox active tyrosine $Y_{z}$ goes with nearly unit quantum efficiency, which requires at least a $100 \mathrm{mV}$ driving force for the reaction, placing the potential for $\mathrm{Y}_{\mathrm{z}}^{+}$at around 1.1 V. Again, oxidation of the manganese cluster is a highly efficient process suggesting that the maximum potential for any $\mathrm{S}$ state conversion is $\approx 1.0 \mathrm{~V}$. Thus, we can see that nature has devised a water oxidizing engine that utilizes $75 \%$ of the 


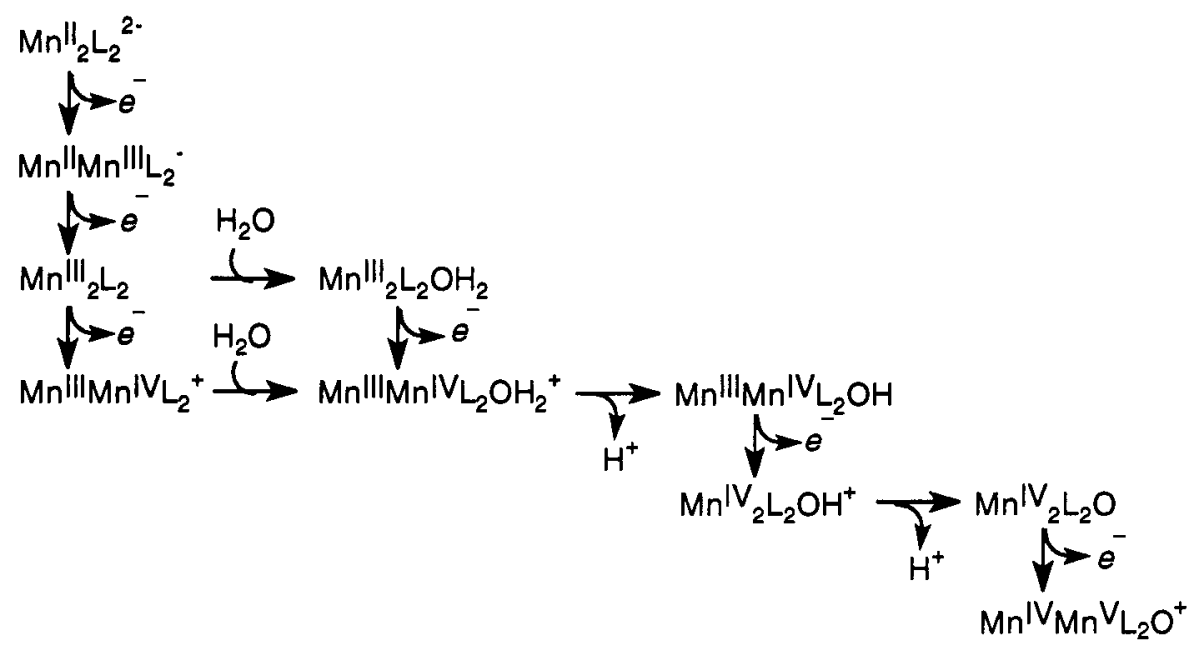

Figure 3

available energy from $\mathrm{P}_{680}$ and maximally wastes $10 \%$ of the available energy at the chemical oxidation step. Even more remarkable is that almost all of this energy is lost on the $S_{0}->S_{1}$ transition which has an estimated potential of $\approx 0.7 \mathrm{~V}$ (ref. 20 ).

Careful reflection on these energetic issues leads to several profound conclusions. First, the $S_{1}$ $->S_{2}, S_{2}->S_{3}$ and $S_{3}->S_{4}$ transitions must average $0.97 \mathrm{~V}$. Second, even if one of these oxidation occurs with little or no driving force (e.g., at $1.1 \mathrm{~V}$ which would sacrifice dioxygen yield), the lowest possible potential for one of the remaining transitions must be $0.8 \mathrm{~V}$ (i.e., $0.7+$ $0.8+1.0+1.1=3.6 \mathrm{~V}$ ). In reality, the estimate of $0.8 \mathrm{~V}$ is probably too low and a value of $0.85-$ $0.9 \mathrm{~V}$ is more realistic. Thus, we can extract relatively precise estimates for the potentials of the manganese cluster in each oxidation state. Furthermore, these values provide insight on the protonation state changes associated with each oxidation of the manganese cluster.

It is well established that the sequential oxidations of oxo and sulfido metal clusters as illustrated in equations 6 and 7 proceed with an increase in potential of $0.3-0.4 \mathrm{~V}$ per oxidation step(ref. 21).

$$
\begin{array}{ll}
\left.\left[\mathrm{M}_{\mathrm{n}} \mathrm{O}_{\mathrm{n}}\right]^{\mathrm{n}+} \cdots \mathrm{M}_{\mathrm{n}} \mathrm{O}_{\mathrm{n}}\right]^{\mathrm{n}+1}+1 \mathrm{e}^{\cdot} & \mathrm{E}=0.0 \mathrm{~V} \\
{\left[\mathrm{M}_{\mathrm{n}} \mathrm{O}_{\mathrm{n}}\right]^{\mathrm{n}+1}-\cdots>\left[\mathrm{M}_{\mathrm{n}} \mathrm{O}_{\mathrm{n}}\right]^{\mathrm{n}+2}+1 \mathrm{e}^{\cdot}} & \mathrm{E}=0.35 \mathrm{~V}
\end{array}
$$

If the $\mathrm{Mn}$ cluster in the OEC behaved in this manner one might predict potentials for the four $\mathrm{S}$ states transitions that are $0.45 \mathrm{~V}\left(\mathrm{~S}_{0}->\mathrm{S}_{1}\right), 0.75 \mathrm{~V}\left(\mathrm{~S}_{1}->\mathrm{S}_{2}\right), 1.05 \mathrm{~V}\left(\mathrm{~S}_{2} \rightarrow \mathrm{S}_{3}\right)$ and $1.35 \mathrm{~V}\left(\mathrm{~S}_{3}\right.$ $-->S_{4}$ ). These values are clearly incorrect based on the preceeding discussion. This energetic quandry can be resolved by recognizing that the potentials for sequential oxidations of oxo and sulfido metal clusters can be leveled by dissipating the resultant positive charge on the cluster. It is observed that the potentials shift by $0.05-0.2 \mathrm{~V}$ per oxidation step in oxidations that do not result in charge accumulation on the cluster(ref. 9, 10). Using an average change of $0.1 \mathrm{~V}$ per step would allow for an oxidation potential progression that is much closer to the estimated potentials $[0.75 \mathrm{~V}$ $\left(\mathrm{S}_{0}-\rightarrow \mathrm{S}_{1}\right), 0.85 \mathrm{~V}\left(\mathrm{~S}_{1}-\rightarrow \mathrm{S}_{2}\right), 0.95 \mathrm{~V}\left(\mathrm{~S}_{2}-\rightarrow \mathrm{S}_{3}\right)$ and $\left.1.05 \mathrm{~V}\left(\mathrm{~S}_{3}->\mathrm{S}_{4}\right)\right]$.

The two easiest ways to dissipate the resultant positive charge on the cluster are either to couple oxidation to the loss of a proton or to the binding of an anion. Both processes are possible in the OEC since four protons must be released during the oxidation of two $\mathrm{H}_{2} \mathrm{O}$ to $\mathrm{O}_{2}$ and chloride anion is an essential cofactor for water oxidation. We favor the loss of protons as the primary mechanism for redox potential leveling. In fact, $\mathrm{H}$ atom abstraction satisfies this energetic criterion, as this process is equivalent to electron and proton loss.

In summary, model compounds have provided the foundation for establishing broad chemical principles that can be used to interpret biophysical experiments of the OEC and provide a model for water oxidation. Consistent with these principles is a water oxidation mechanism that is provided as Fig. 1. Future tests of this model will require preparation of $\mathrm{Mn}^{\mathrm{N}} \mathrm{Mn}^{\mathrm{v}}=\mathrm{O}$ dimers and the characterization of tetrameric species capable of both peroxide generation and hydrogen peroxide oxidation. 


\section{References}

1. R. D. Britt. In Oxygenic Photosynthesis: The Light Reactions (D. R. Ort and C. F. Yocum, ed), pp. 137164. Kluwer, Academic Publishers, The Netherlands (1996).

2. V. K. Yachandra, K. Sauer and M. P. Klein. Chem. Rev. 96, 2927 (1996).

3. G. T. Babcock. In Photosynthesis: from Light to Biosphere (P. Mathis, ed), pp. 209-215. Kluwer Academic Publishers, Netherlands (1995).

4. C. W. Hoganson, N. Lydakis-Simantris, X. Tang, C. Tommos, K. Warncke, G. T. Babcock, B. A. Diner, J. MoCracken and S. Styring. Photosynth. Res. 46, 177-184 (1995).

5. M. L. Gilchrist, J. A. Ball, D. W. Randall and R. D. Britt. Proc. Nat. Acad. Sci., USA 92, 9545-9549 (1995).

6. J. Lind, S. X., T. E. Eriksen and G. Merenyi. J. Am. Chem. Soc. 112, 479-482 (1990).

7. F. G. Bordwell and J.-P. Cheng. J. Am. Chem. Soc. 113, 1736-1743 (1991).

8. D. F. McMillen and D. M. Golden. Ann. Rev. Phys. Chem. 33, 493 (1982).

9. M. J. Baldwin and V. L. Pecoraro. J. Am. Chem. Soc. 118, 11325 (1996).

10. M. T. Caudle and V. L. Pecoraro. J. Am. Chem. Soc. 119, 3415 (1997).

11. K. A. Gardner and J. M. Mayer. Science 269, 1849-1851 (1995).

12. H. H. Thorp, J. E. Sarneski, G. W. Brudvig and R. H. Crabtree. J. Am. Chem. Soc. 111, 9249-9250 (1989).

13. S. R. Cooper and M. J. Calvin. J. Am. Chem. Soc. 99, 6623-6630 (1977).

14. E. J. Larson and V. L. Pecoraro. J. Am. Chem. Soc. 113, 3810-3818 (1991).

15. J. Limburg, G. W. Brudvig and R. H. Crabtree. J. Am. Chem. Soc. 119, 2761.2762 (1997).

16. P. J. Riggs-Gelasco, R. Mei, C. F. Yocum and J. E. Penner-Hahn. J. Am. Chem. Soc. 118, 2387-2399 (1996).

17. S. Chang, R. M. Heid and E. N. Jacobsen. Tetrahedron Lett. 35, 669-672 (1991).

18. W. Zhang and E. N. Jacobsen. J. Org. Chem. 56, 2296-2298 (1991).

19. G. T. Babcock, B. A. Barry, R. J. Debus, C. W. Hoganson, M. Atamian, L. McIntosh, I. Sithole and C. F. Yocum. Biochemistry 28, 9557-9565 (1989).

20. H. Wincenjusz, C. Yocum and H. J. Van Gorken. personal communication .

21. A. Gelasco, M. L. Kirk, J. W. Kampf and V. L. Pecoraro. Inorg. Chem. 36, 1829-1837 (1997). 